\title{
Comparative Mitochondrial Genome Analysis of Two Ectomycorrhizal Fungi (Rhizopogon) Reveals Dynamic Changes of Intron and Phylogenetic Relationships of the Subphylum Agaricomycotina
}

\author{
Qiang Li, Yuanhang Ren, Xiaodong Shi, Lianxin Peng, Jianglin Zhao $®$, Yu Song and Gang Zhao* \\ Key Laboratory of Coarse Cereal Processing, Ministry of Agriculture and Rural Affairs, College of Pharmacy and \\ Biological Engineering, Chengdu University, Chengdu 610106, Sichuan, China; leeq110@126.com (Q.L.); \\ renyuanhang@cdu.edu.cn (Y.R.); shixiaodong@cdu.edu.cn (X.S.); penglianxin@cdu.edu.cn (L.P.); \\ jlzhao@cdu.edu.cn (J.Z.); songyu@cdu.edu.cn (Y.S.) \\ * Correspondence: zhaogang@cdu.edu.cn; Tel.: +86-028-84616653
}

Received: 20 September 2019; Accepted: 17 October 2019; Published: 18 October 2019

\begin{abstract}
In the present study, we assembled and compared two mitogenomes from the Rhizopogon genus. The two mitogenomes of $R$. salebrosus and R. vinicolor comprised circular DNA molecules, with the sizes of $66,704 \mathrm{bp}$ and 77,109 bp, respectively. Comparative mitogenome analysis indicated that the length and base composition of protein coding genes (PCGs), rRNA genes and tRNA genes varied between the two species. Large fragments aligned between the mitochondrial and nuclear genomes of both $R$. salebrosus $(43.41 \mathrm{~kb})$ and $R$. vinicolor $(12.83 \mathrm{~kb})$ indicated that genetic transfer between mitochondrial and nuclear genomes has occurred over evolutionary time of Rhizopogon species. Intronic regions were found to be the main factors contributing to mitogenome expansion in $R$. vinicolor. Variations in the number and type of introns in the two mitogenomes indicated that frequent intron loss/gain events occurred during the evolution of Rhizopogon species. Phylogenetic analyses based on Bayesian inference (BI) and Maximum likelihood (ML) methods using a combined mitochondrial gene set yielded identical and well-supported tree topologies, wherein Rhizopogon species showed close relationships with Agaricales species. This is the first study of mitogenomes within the genus Rhizopogon, and it provides a basis for understanding the evolution and differentiation of mitogenomes from the ectomycorrhizal fungal genus.
\end{abstract}

Keywords: Rhizopogon; mitochondrial genome; intron; gene rearrangement; evolution; phylogenetic analysis

\section{Introduction}

The genus Rhizopogon, (Boletales, Basidiomycota), is an important ectomycorrhizal fungal group, which was widely distributed in Europe and North America [1-5]. The genus forms hypogeous sporocarps, commonly referred to as 'false truffles'. Rhizopogon species form ectomycorrhizal associations with trees in the family Pinaceae, primarily Pinus and Pseudotsuga spp. Through their ectomycorrhizal relationships, Rhizopogon species obtains carbon sources necessary for growth, and in exchange they provide trees with access to water and mineral nutrients [1]. In addition, ectomycorrhizal fungi, e.g., Rhizopogon spp., promote plant growth, enhance plant resistance to stress and maintain the forest ecosystem [6-8]. The genus Rhizopogon is diverse, with more than 150 species described $[3,9,10]$. However, it is difficult to identify and classify Rhizopogon species accurately because of the limited morphological characteristics that can be distinguished and the overlapping of some morphological features. The uniparental inheritance, rapid evolution rate and availability of molecular markers [11] 
have made mitochondrial genome powerful tools for studying evolutionary biology, phylogenetics and taxonomy of Eukaryotes [12,13]. Up to now, no mitochondrial genomes have been assembled from sequence data in the genus, which limits our understanding of this important ectomycorrhizal fungal group.

Mitochondria are the main chemical energy suppliers for aerobic, free-living eukaryotes, and play an important role in growth, development, aging and stress resistance [14,15]. Mitochondria contain their own genomes, commonly known as the "second genome" of eukaryotes [16], and hereafter referred to as mitogenomes. There are 20-36 tRNA genes, 1-2 rRNA genes, a series of genes for energy metabolism, and several regulatory genes found in eukaryotic mitogenomes [17]. Mitogenomes from different eukaryotic groups have undergone tremendous diversification in genome size, and in gene content, structure, and arrangement [18-20]. Mitogenomes of animals have been extensively studied, and more than 8000 animal mitogenomes have been reported in the NCBI database (https://www.ncbi.nlm.nih.gov/genome/browse\#!/organelles/), and these have promoted the development of animal taxonomy and genetics [21,22]. However, mitogenomes in fungi, especially in Agaricomycotina, have been less studied than the animal counterpart [23], although they were initially targeted in early work using mt-rRNA genes or selected mt-protein genes. As the largest mushroom-forming fungal group, less than 80 Agaricomycotina mitogenomes have been reported, which limits the understanding of the "second genome" of the mushroom-forming fungi. It was reported that the evolution rate of mitogenomes from fungi was intermediate to that of animals (highest mutation rate) and plants (lowest mutation rate) [24]. Previous studies found that mitogenomes of fungi differed greatly in genome size, content of repeat sequence, gene arrangement, and genome organization [25-27]. However, most Agaricomycotina mitogenomes were found to contain 14 core protein coding genes (PCGs), including atp6, atp8, atp9, cob, cox1, cox2, cox3, nad1, nad2, nad3, nad4, nad4L, nad5, and nad6, for energy metabolism plus one rps3 gene for transcriptional regulation; collectively we call this set of the genes the core PCGs of Agaricomycotina. The features and variations of mitogenome size, organization and gene content of Rhizopogon species are helpful to reveal the evolution and phylogeny of Rhizopogon species.

Introns are common in mitogenomes of fungi, and they are considered to be one of the main factors contributing to variations in the size and organization of fungal mitogenomes [28,29]. Introns in the mitogenomes of fungi can be divided into two groups, namely, I and II. The cox1 gene was found to be the main host gene of introns in fungal mitogenome [30]. In addition, introns were also detected in other mitochondrial genes, such as the cox2, cob, nad1, nad5 and $r n l$ [31]. Mitochondrial introns can behave as mobile genetic elements [32,33]. Homologous introns often have the same insertion sites in the coding region of host genes and also have high sequence similarities [30]. Introns can be divided into different position classes (Pcls) according to their insertion sites in the coding region of PCGs, while the same Pcls generally contain homologous intronic ORFs [30], which encode homing endonucleases. The number and type of introns varied greatly between different fungal species [30]. Up to known, the intron information in Rhizopogon genus has not been revealed.

In the present study, the complete mitogenomes of R. salebrosus and R. vinicolor were assembled and annotated. The gene content, tRNA structure, repeat sequences, intron information and genome organization of the two mitogenomes were analyzed. We also compared the two mitogenomes to identify variations and similarities in genome organization, gene content, and gene order. In addition, the phylogenetic relationships among various Agaricomycotina species were analyzed based on combined mitochondrial gene sets. As an important ectomycorrhizal fungus, the Rhizopogon species plays an important role in maintaining the forest ecosystem and promoting a natural carbon and nitrogen cycle. The mitogenomes of the two Rhizopogon species in this study further our understanding of the genetics, taxonomy, and evolutionary biology of the ectomycorrhizal fungi, and other related fungal species. 


\section{Results}

\subsection{Features and Protein Coding Genes of the Rhizopogon Mitogenomes}

The complete mitogenomes of $R$. salebrosus and $R$. vinicolor were composed of circular DNA molecules, with the total size of $66,704 \mathrm{bp}$ and77,109 bp, respectively (Figure 1). The GC content of $R$. salebrosus and $R$. vinicolor mitogenomes were $21.45 \%$ and $21.46 \%$, respectively. Both mitogenomes contained negative AT skews and positive GC skews (Table S1). A total of 24 and 22 non-intronic ORFs were detected in the mitogenomes of $R$. salebrosus and $R$. vinicolor, respectively, including 15 core PCGs (atp6, atp8, atp9, cob, cox1, cox2, cox3, nad1, nad2, nad3, nad4, nad4L, nad5, nad6, and rps3) and several non-core PCGs (Table S2). The R. salebrosus mitogenome contains 9 non-intronic PCGs, 3 of which encoded B-type DNA polymerase, and the other six have unknown functions. The $R$. vinicolor mitogenome contained 7 additional non-intronic ORFs, which included 2 B-type DNA polymerase genes and 5 PCGs with unknown function. We detected 16 and 24 introns in the mitogenomes of $R$. salebrosus and R. vinicolor, respectively. All of these introns belonged to the group I. In addition, 10 and 19 intronic ORFs were detected in the mitogenome of $R$. salebrosus and $R$. vinicolor, respectively, which encoded LAGLIDADG or GIY-YIG homing endonucleases.

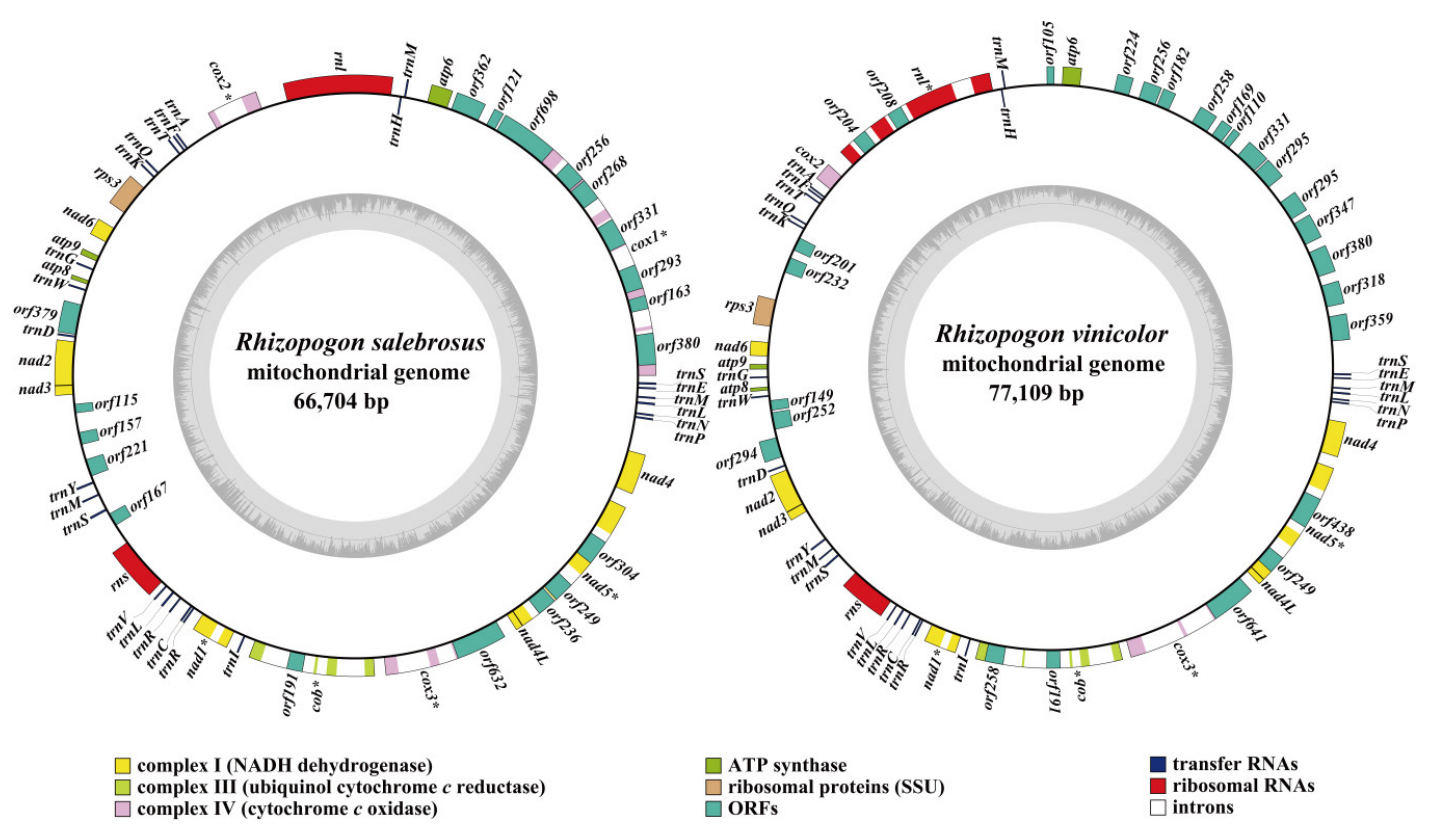

Figure 1. Circular maps of the mitogenomes of two Rhizopogon species. Genes are represented by different colored blocks. Colored blocks outside each ring indicate that the genes are on the direct strand, while colored blocks within the ring indicates that the genes are located on the reverse strand. The circle inside the GC content graph marks the 50\% threshold.

\subsection{RNA Genes in the Rhizopogon Mitogenomes}

Two rRNA genes were detected in the mitogenomes of $R$. salebrosus and $R$. vinicolor, namely the small subunit ribosomal RNA ( $r n s)$, and the large subunit ribosomal RNA ( $r n l$ ) (Table S2). Twenty-five tRNA genes were detected in the two mitogenomes, which were folded into classical cloverleaf structures (Figure 2). The two mitogenomes both contained 2 isoacceptors with different anticodons for serine, arginine, and leucine, and 3 isodecoders with the same anticodon for methionine. The length of individual tRNAs ranged from $71 \mathrm{bp}$ to $88 \mathrm{bp}$, which was mainly due to variations of extra arms. Of the 25 tRNA genes detected in the two mitogenomes, 13 contained sites that varied between the two mitogenomes. The most common variable site was located on the acceptor stem (six sites varied between the two mitogenomes), followed by the D arm that contained four variable sites. 


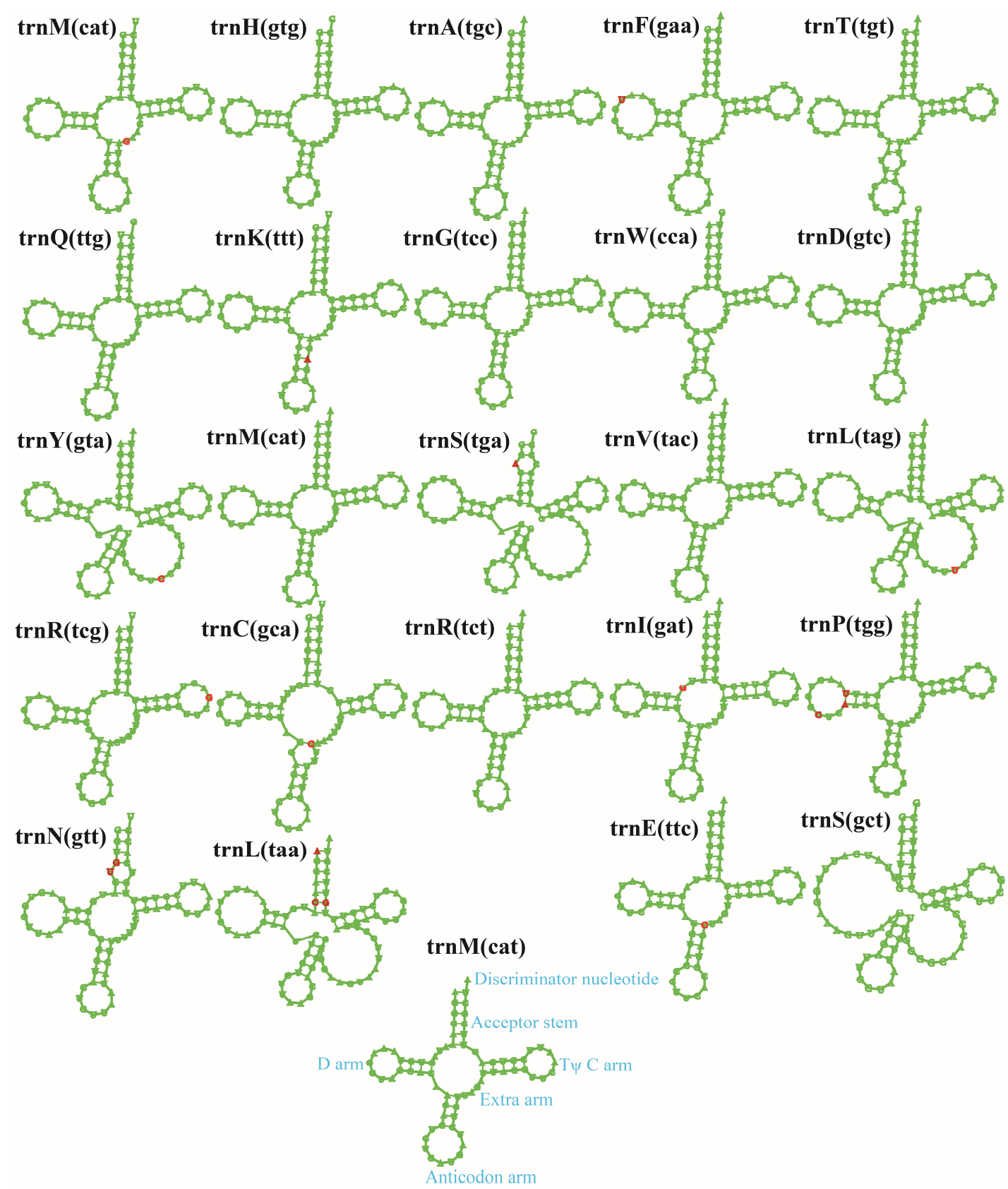

Figure 2. Putative secondary structures of the 25 tRNA genes identified in the mitogenomes of two Rhizopogon species. Residues conserved across the two mitogenomes are shown in green, while variable sites are shown in red. All genes are shown in order of occurrence in the mitogenome of $R$. salebrosus, starting from trnM.

\subsection{Overlapping Nucleotides and Composition of Mitogenomes}

We detected four overlapping nucleotides in the mitogenome of $R$. salebrosus, with the largest overlapping nucleotides located across the neighboring genes cox3 and orf632 ( $-85 \mathrm{bp}$ ) (Table S2). Three sets of overlapping nucleotides were detected in the mitogenome of $R$. vinicolor, and the largest set of overlapping nucleotides was located between cox3 and orf641 ( $-85 \mathrm{bp}$ ). A total of $18,577 \mathrm{bp}$ and $18,040 \mathrm{bp}$ of intergenic sequences were identified in the mitogenome of $R$. salebrosus and $R$. vinicolor, respectively. The length of intergenic sequences ranged from $37 \mathrm{bp}$ to $1791 \mathrm{bp}$, and the longest intergenic sequence was located between orf105 and trnM in the $R$. vinicolor mitogenome. 
The protein coding region accounted for the largest proportion of the R. salebrosus mitogenome, totaling $33.89 \%$ (Figure 3). Intronic regions occupied the largest proportion of the $R$. vinicolor mitogenome, accounting for $41.01 \%$. RNA coding regions (tRNA and rRNA) accounted for the smallest proportion of the two mitogenomes (10.09-11.67\%). The mitogenome of $R$. vinicolor was 10,405 bp larger than that of $R$. salebrosus. Intronic regions contributed the most to the mitogenome expansion in $R$. vinicolor, totaling $133.45 \%$ of the size difference (Figure 3). Protein coding regions contributed $-28.26 \%$ of the increased size, and intergenic regions contributed $-5.16 \%$ of the $R$. vinicolor mitogenome expansion. These results indicated that the expansion of the $R$. vinicolor mitogenome was primarily due to the increase of intronic regions.
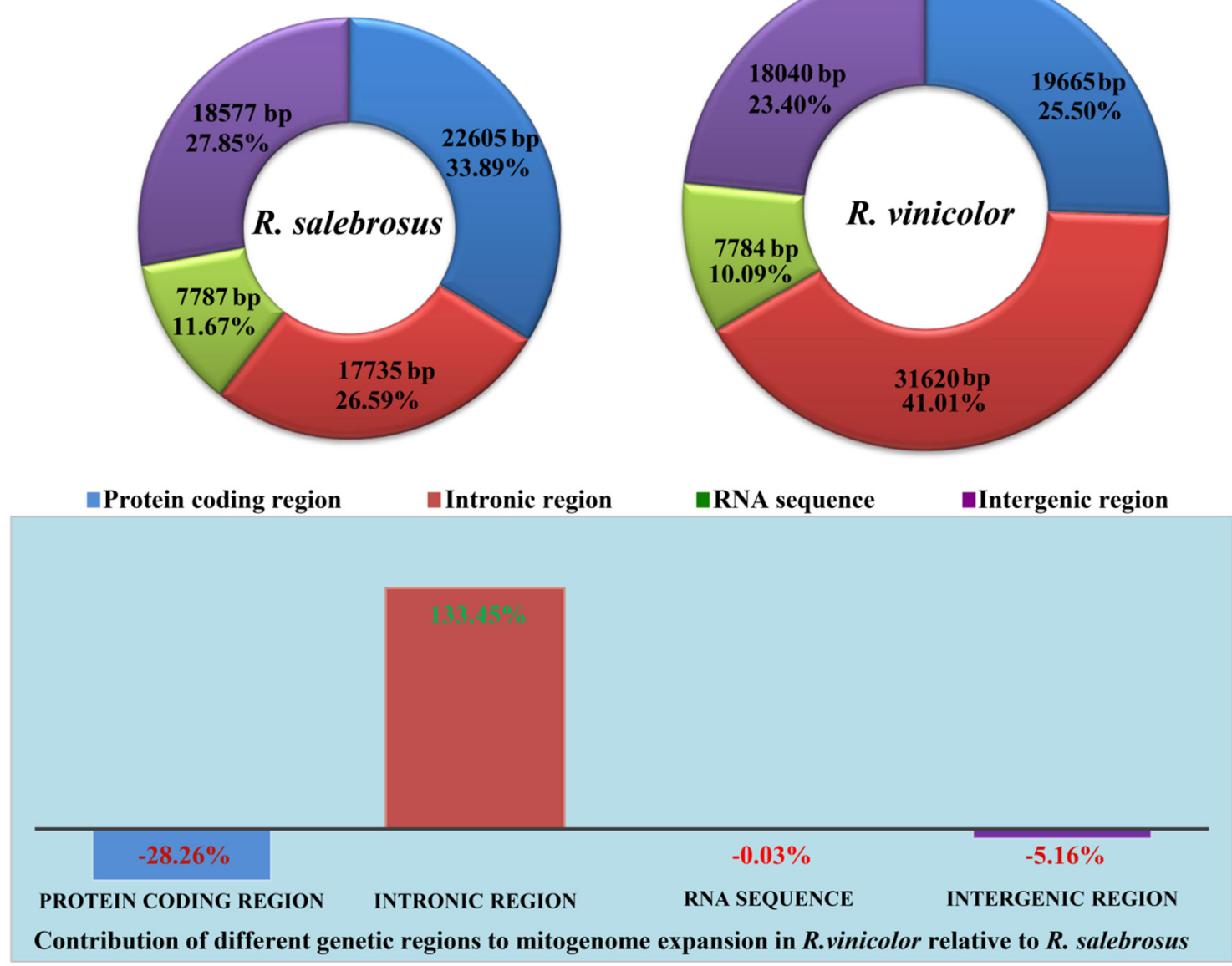

Figure 3. The protein-coding, intronic, intergenic, and RNA gene region proportions of the entire mitogenomes of the two Rhizopogon species. The bottom panel shows the contribution of different gene regions to the expansion of the $R$. vinicolor mitogenome.

\subsection{Codon Usage Analysis}

All the 12 Agaricales and 2 Boletales species tested used the universal mitochondrial code. As shown in Table S3, most core PCGs used ATG as start codons and TAA as stop codons in the two Rhizopogon species. However, cob genes in the two Rhizopogon species used TAG as stop codons, just like the cob gene of Agaricus bisporus [30]. Cox1 genes of the two Rhizopogon species used TTG as start codons, just as Moniliophthora species [34,35] from the order Agaricales.

Codon usage analysis indicated that the most frequently used codons in the two mitogenomes were TTA (for leucine; Leu), TTT (for phenylalanine; Phe), AAT (for asparagine; Asn), ATT (for isoleucine; Ile), AAA (for lysine; Lys), and TAT (for tyrosine; Tyr) (Figure 4). The frequent use of A and $\mathrm{T}$ in codons contributed to the high AT content in the Rhizopogon mitogenomes (average: $78.55 \%$ ). 

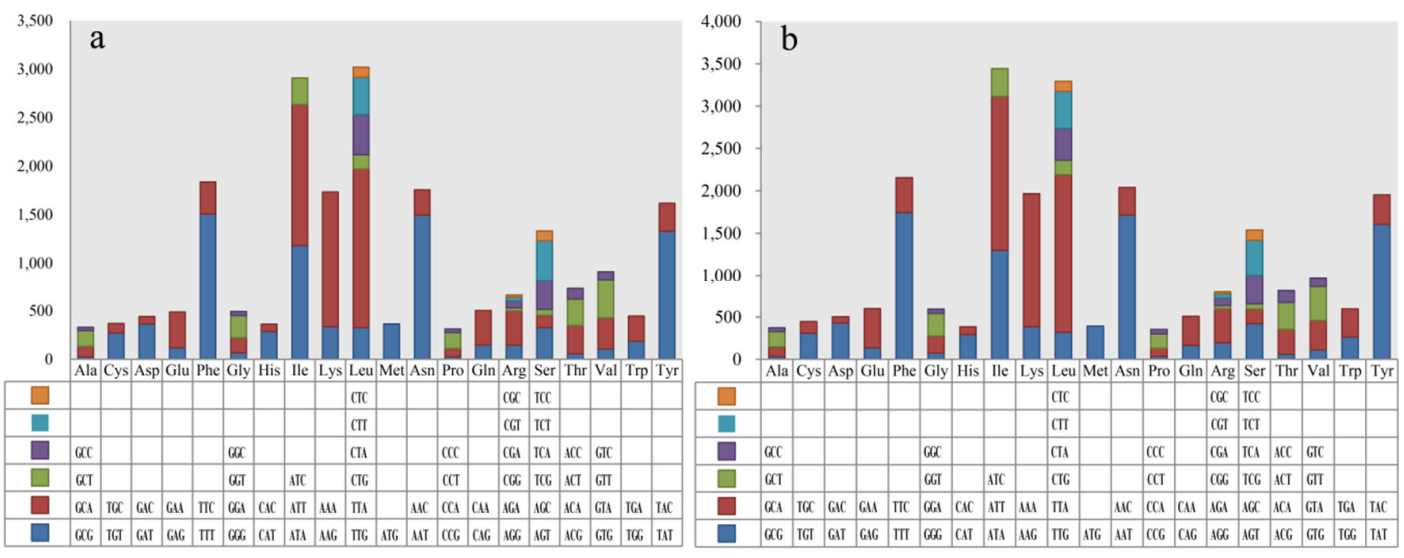

Figure 4. Codon usage in the mitogenomes of two Rhizopogon species. Frequency of codon usage is plotted on the y-axis. (a) R. salebrosus; (b) R. vinicolor.

\subsection{Repetitive Sequences Analysis}

Comparing the whole mitogenomes of $R$. salebrosus and $R$. vinicolor with themselves via BLASTn searches, we identified 12 repeat sequences in the mitogenome of $R$. vinicolor (Table S4). No repeat sequence was identified in the $R$. salebrosus mitogenome. The length of repeat sequences in the $R$. vinicolor mitogenome ranged from $39 \mathrm{bp}$ to $810 \mathrm{bp}$, with pair-wise nucleotide similarities ranging from $80.37 \%$ to $100 \%$. The largest repeats were observed in the intergenic region between orf105 and trnM, as well as in the intergenic region between orf232 and rps3. The second largest repeats were found located in the intergenic region between orf105 and $\operatorname{trnM}$, as well as in intergenic region between trnK and orf201, with each repeating sequence $163 \mathrm{bp}$ long. Repeat sequence accounts for $3.01 \%$ of the $R$. vinicolor mitogenome.

A total of 63 and 64 tandem repeats were identified in the mitogenomes of R. salebrosus and $R$. vinicolor, respectively (Table S5). The longest tandem repeat sequence was observed in the $R$. vinicolor mitogenome, comprising $116 \mathrm{bp}$, which was located in the intergenic region between orf 249 and orf438. Most of the tandem repeats were duplicated once or twice in the two mitogenomes, with the highest replication number (13) in the $R$. vinicolor mitogenome. Tandem repeat sequences accounted for $5.36 \%$ and $4.39 \%$ of the R. salebrosus and R. vinicolor mitogenomes, respectively. REPuter identified 6 forward, and 1 reverse repeats in the mitogenome of $R$. salebrosus, accounting for $0.73 \%$ of the entire mitogenome (Table S6). A total of 34 forward, 4 palindromic, and 12 reverse repeats were detected in the mitogenome $R$. vinicolor, which accounted for $2.53 \%$ of the total mitogenome.

To identify gene segments that may have been transferred between the nuclear and mitogenomes, we blasted the two mitogenomes against their nuclear genomes. A total of 55 and 30 aligned fragments were detected in the mitogenome of R. salebrosus and R. vinicolor, respectively (Table S7). The length of these aligned fragments ranged from $30 \mathrm{bp}$ to $3005 \mathrm{bp}$, with sequence identities between $80.37 \%$ and $100 \%$. The largest aligned fragment was found located in the protein coding regions of cox 1 gene in the $R$. salebrosus mitogenome. The largest aligned fragment in the $R$. vinicolor mitogenome (2376 bp) was found encompassed in the protein coding regions orf232 and rps3, as well as the intergenic region between them. The presence of large fragments that aligned between the mitochondrial and nuclear genomes of the two Rhizopogon mitogenomes indicated that genetic transfer between mitochondrial and nuclear genomes may have occurred over evolutionary time of Rhizopogon species.

\subsection{Variation, Genetic Distance, and Evolutionary Rates of Core Genes}

Among the 15 core PCGs detected, 3 PCGs varied in length between the two Rhizopogon species, including nad3, nad4 and rps3 (Figure 5). The length of nad3 gene had the greatest variation, and there were 7 amino acid variations between the two Rhizopogon species. The GC content for each of the core 
PCGs varied between the two Rhizopogon species, except for that of the atp9 gene. AT skews of core PCGs used for energy metabolism were negative in both Rhizopogon species, while rps3, which is used for transcriptional regulation, was positive in the two mitogenomes. The GC skews of core PCGs in the two mitogenomes were variable. The atp 6 and atp 8 genes contained negative GC skews in both species. GC skews in nad2 and nad6 genes of the R. salebrosus mitogenome were negative, while they were 0 in the two genes of the $R$. vinicolor mitogenome. The length of tRNA genes was conservated between the two Rhizopogon species. The trnS gene had the longest length among the 25 tRNA genes detected in the two mitogenomes, followed by the $t r n L$ gene, due primarily to their relatively long extra arm. Ten of the 25 tRNA genes each showed variations in GC content between the two Rhizopogon species, suggesting that PCGs and tRNA genes in Rhizopogon species undergo frequent base variation.
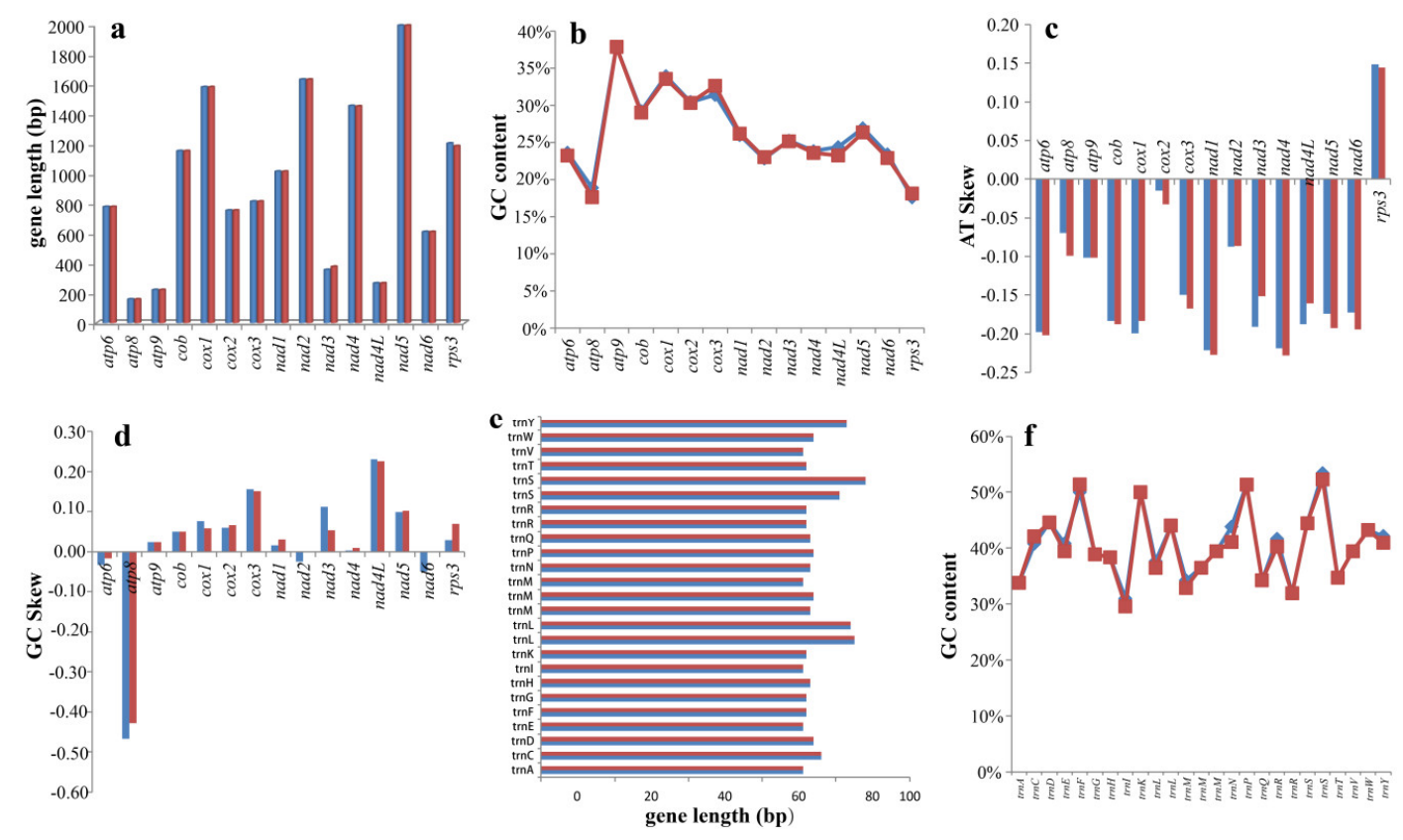

Figure 5. Variation in the length and base composition of each of 15 protein-coding genes (PCGs) and 25 tRNA genes between two Rhizopogon mitogenomes. R. salebrosus is represented in blue and $R$. vinicolor is represented in red. (a) PCG length variation; (b) GC content of the PCGs; (c) AT skew; (d) GC skew; (e) lengths of shared tRNA genes; (f) GC content of shared tRNA genes.

Among the 15 core PCGs detected, rps3 gene had the largest K2P genetic distance between the two Rhizopogon species, followed by nad6 gene (Figure 6). The K2P genetic distance of atp 9 gene between two Rhizopogon species was the smallest, indicating that it was highly conserved between Rhizopogon species. The cox3 gene had the largest synonymous substitutions rate (Ks) among the 15 core PCGs, while atp 9 had the smallest Ks value. The nonsynonymous substitution rate (Ka) of atp8 gene was 0 , while that of rps3 gene was the largest in the Rhizopogon species. The Ka/Ks values of the 15 core PCGs ranged from 0 to 0.69 , indicating that these genes were subjected to purifying selection. 


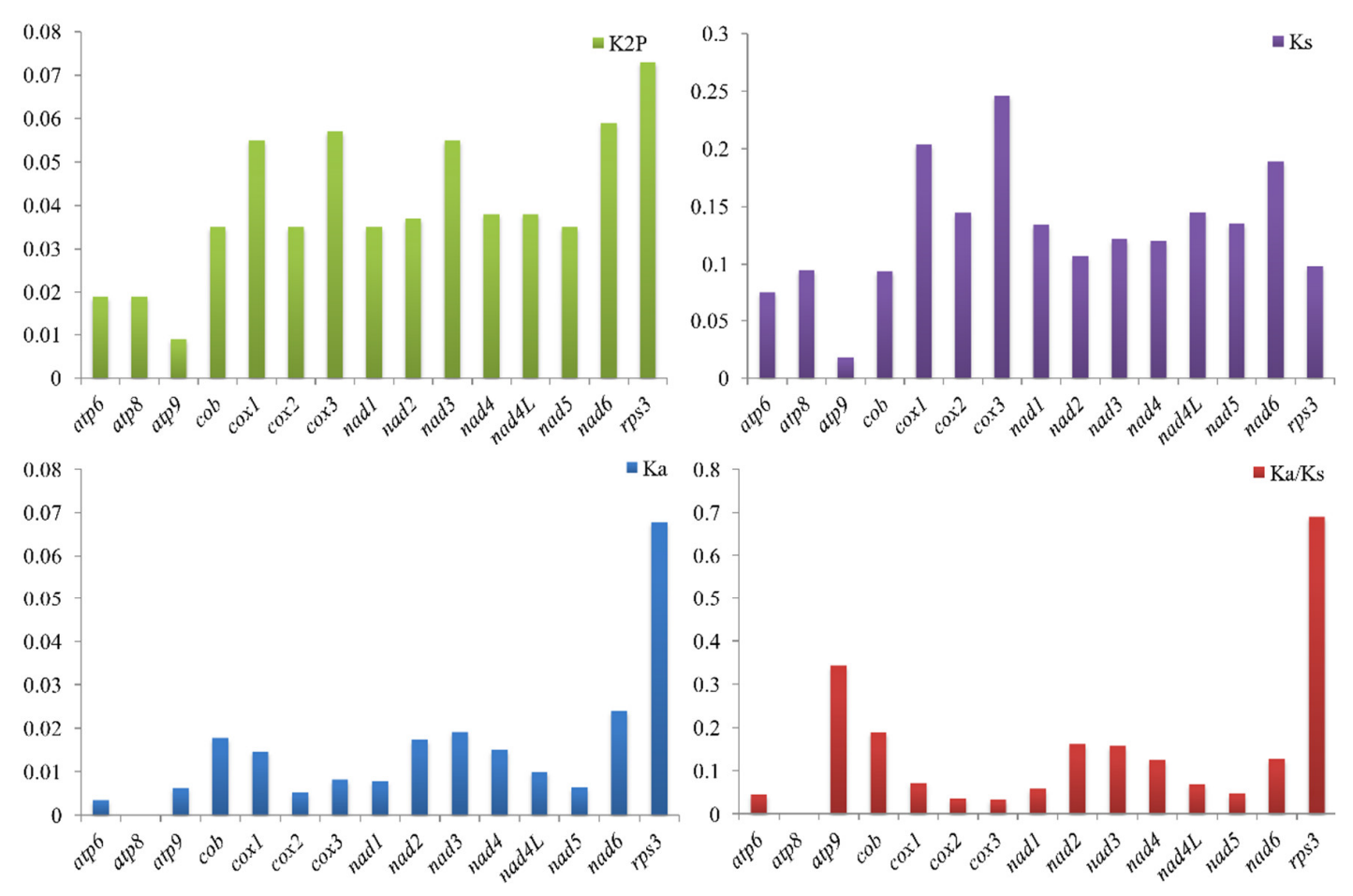

Figure 6. Genetic analysis of 15 protein coding genes conserved in two Rhizopogon mitogenomes. K2P - the Kimura-2-parameter distance; $\mathrm{Ka}$ - the mean number of nonsynonymous substitutions per nonsynonymous site; Ks — the mean number of synonymous substitutions per synonymous site.

\subsection{Dynamic Changes of Introns in Rhizopogon Mitogenomes}

A total of 40 introns were detected in mitogenomes of the two Rhizopogon species, which were distributed in $\operatorname{cox} 1, \operatorname{cox} 2, \operatorname{cox} 3, c o b, n a d 1, n a d 5$ and $r n l$ genes. The cox1 gene hosted the largest number of introns in Rhizopogon species with 18 of 40 introns located in it (Table S8). The cob gene hosted the second largest number with 7 introns. Each intron harboured 0-2 homing endonuclease genes, including the LAGLIDADG type 1 homing endonuclease, the LAGLIDADG type 2 homing endonuclease and GIY-YIG endonuclease. Several intron types were detected in the mitogenomes of Rhizopogon species, with the most common type being Group IB, followed by the Group ID. Two introns with novel types were found in $c o b$ and $r n l$ genes of the two Rhizopogon mitogenomes. The 18 introns in cox1 genes of the two Rhizopogon species could be classified into 14 Pcls according to their insertion positions in the coding region of PCGs. Among them, 11 were homologous with Pcls from previously reported mitogenomes [30], while the other three were unknown Pcls that were unique in one of the two Rhizopogon species. Pcls K, S, AC and AD were detected in both Rhizopogon species and were widely distributed in other species of fungi. Pcl P was detected only in the cox 1 gene of $R$. salebrosus, but were also present in distantly related species, such as Agaricus bisporus [30] and Pleurotus ostreatus [25]. Pcls D, $\mathrm{G}, \mathrm{H}, \mathrm{N}, \mathrm{AA}, \mathrm{AI}$ found in the mitogenome of $R$. vinicolor, were also present in plants such as Marchantia polymorpha, Beta vulgaris, Plantago atrata, and others [30]. In cox2 gene, $R$. salebrosus contained an intron inserted at $543 \mathrm{nt}$ of the protein coding region, and homologous intron was not detected in another Rhizopogon species R. vinicolor. Non-homologous introns between the two mitogenomes accounted for $50 \%, 14.29 \%, 60 \%$ and $100 \%$ of the total introns in cox3, cob, nad5 and $\mathrm{rnl}$ genes, respectively. Variations of the number and Pcl of introns between the two mitogenomes indicated that frequent intron loss/gain occurred in the evolution of Rhizopogon species. Homologous introns in Rhizopogon species were also found in distant species from other orders, indicating possible horizontal gene transfer events. 


\subsection{Gene Arrangement and Phylogenetic Analysis}

The arrangement of mitochondrial genes could be used as a reference for studying the phylogenetic status and evolution of species. In the present study, we used Mauve to analyze the collinearity of mitogenomes between two Rhizopogon species and 16 other species from Agaricomycetes. The results showed that the arrangement of mitochondrial genes in Agaricomycetes species were highly variable (Figure S1). Several homologous regions were detected between the 18 species of Agaricomycetes. The size and location of these homologous regions varied greatly between the 18 species, even between species from the same genera, such as the Cantharellus, Pleurotus and Ganoderma genera. However, a high degree of collinearity was found between two species from the genus Rhizopogon. The results showed that Rhizopogon species were conservative in gene arrangement during evolution.

Phylogenetic analysis based on BI and ML methods using the combined mitochondrial gene set (15 core PCGs +2 rRNA genes) yielded identical and well-supported tree topologies (Figure 7). All major clades within the trees were well supported (BPP = 1.00; $\mathrm{BS} \geq 97$ ). Based on the phylogenetic tree, the 41 Agaricomycotina species could be divided into six major clades, corresponding to the orders Tremellales, Cantharellales, Agaricales, Boletales, Russulales, and Polyporales (Table S9). Cantharellales species in Agaricomycotina were distant from other Agaricomycetes species, indicating their early differentiation from other species in Agaricomycetes. Phylogenetic analysis also showed that Boletales had a relatively recent phylogenetic relationship with Agaricales and Polyporales. The analysis further indicated that $R$. salebrosus were a sister species to R. vinicolor. Phylogenetic analyses based on mitochondrial genes were consistent with that based on nuclear genes [36]. The results indicated that the combined mitochondrial gene dataset was suitable as a reliable molecular marker for the analysis of phylogenetic relationships between Agaricomycotina species.

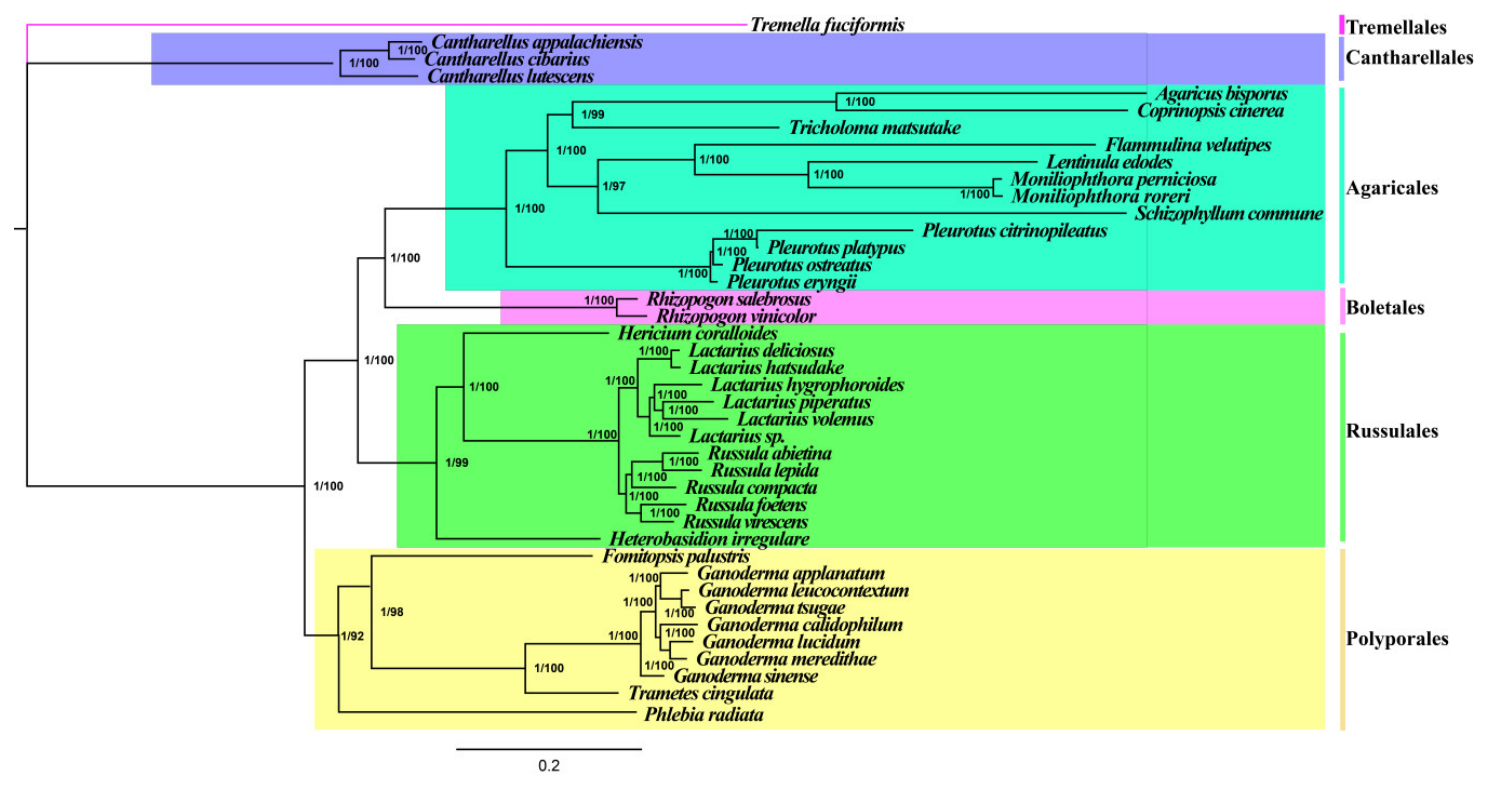

Figure 7. Molecular phylogeny of 41 Agaricomycotina species based on Bayesian inference (BI) and Maximum likelihood (ML) analysis of 15 protein coding genes and two rRNA genes. Support values are Bayesian posterior probabilities (before slash) and bootstrap (BS) values (after slash). Species and NCBI accession numbers for genomes used in the phylogenetic analysis are provided in Supplementary Table S9.

\section{Discussion}

The mitogenome size of fungi varied greatly compared with that of other eukaryotic groups [37]. Interspecific and intraspecific fungal species exhibited high variabilities in mitogenome size, which was mainly due to the variation of introns, the accumulation of repetitive sequences, intergenic sequences 
and horizontal transferred genes [31,34,38]. In the present study, we found that mitogenomes of the two Rhizopogon species were of medium size, smaller than those of Phlebia radiate [30,39], A. bisporus [30] and Lentinula edodes [40], and larger than those of Coprinopsis cinerea [41] and Schizophyllum commune [42], which all belonged to the Agaricomycotina. Mitogenome size also varied greatly between the two species in the Rhizopogon genus. Mitogenome expanded 10,405 bp in R. vinicolor species, and intron was found to be the most important factor leading to mitogenome expansion in $R$. vinicolor. The result was consistent with previous studies that intron variation was one of the main factors contributing to the variability of fungal mitogenome size [30,43].

Since the mitogenome of eukaryotes was obtained from the common ancestor Alphaproteobacteria [19,44], it has evolved differently in multiple lineages to form the morphology and structure it now possesses. In the course of evolution, most of the mitochondrial genes were transferred to the nuclear genome [45]. Only genes, such as the mitochondrial respiratory chain related genes, tRNA genes, rRNA genes, and some regulatory genes were retained in the mitogenome. Up to now, almost all published basidiomycete mitogenomes contained 15 core PCGs (atp6, atp8, atp9, cob, $\operatorname{cox} 1, \operatorname{cox} 2, \operatorname{cox} 3$, nad1, nad2, nad3, nad4, nad4L, nad5, nad6, rps3). However, we found that the length and base composition of the core PCGs varied greatly between mitogenomes of the two Rhizopogon species, as well as other basidiomycetes [46,47]. In addition, different core PCGs exhibited variable genetic distances between the two Rhizopogon mitogenomes, which shows that the evolutionary rates of these core genes vary. It was also found that the core PCGs were subjected to purifying selection in the two Rhizopogon species. The evolutionary characteristics of mitochondrial core PCGs provided important information for studying phylogenetic and genetics of fungal species. In addition, some non-conservative PCGs were detected in fungal mitogenomes, including DNA polymerase, RNA polymerase and some PCGs with unknown function. Further studies are needed to elucidate the origin, distribution, function and phylogenetic relationships of these unknown functional genes to fully understand the evolution and function of mitogenome. Different numbers of tRNA genes had also been detected in fungal mitogenomes, which varied in base composition and gene length. In this study, we found that 13 of the 25 tRNA genes shared by Rhizopogon species had site variations between the two Rhizopogon species. Mitochondrial tRNA mutation has been found to affect amino acid transport efficiency and protein synthesis in other eukaryotes $[48,49]$. The effects of tRNA variations on fungal growth and mitochondrial function are still unknown.

The mitochondrial gene arrangement could also be used to reveal the evolutionary and phylogenetic relationships of species [50,51]. Mitochondrial gene rearrangements have been extensively studied in animals, and several models have been proposed to reveal the mechanism of mitogenome rearrangements [52,53]. However, compared with animals, the mitochondrial gene order of fungi is highly variable, even among closely related species [25]. Up to now, mitochondrial gene rearrangements have been detected in most of the mushroom-forming (Agaricomycetes) fungal mitogenomes, such as Pleurotus spp. [25], Lyophyllum spp. [31], Lactarius spp. [26], Russula spp. [27], and Cantharellus spp. [54]. This may be due to the accumulation of repetitive sequences in mitogenomes of these fungi [24]. However, we found a high degree of collinearity between the two Rhizopogon species, suggesting that the gene arrangement of the two Rhizopogon species was conservative in the evolutionary process. A small number of repetitive sequences in mitogenomes were considered to be one of the reasons for conservative gene arrangement in Rhizopogon species.

Introns are considered as mobile genetic elements in mitogenomes of eukaryotes. The dynamic changes of introns could affect the organization and size of mitogenomes [29,33]. Introns could be classified into different Pcls according to their insertion positions in the coding region of PCGs [30]. Introns belonging to the same Pcl were considered to be orthologous and had high sequence similarities. Homologous intronic ORFs were found in introns from the same Pcls. In the present study, we found that the number and Pcl of introns were highly variable between the two Rhizopogon species, suggesting that frequent intron loss/gain occurred during the evolution of Rhizopogon species. In addition, introns 
homologous to Rhizopogon species were detected in other distant species, indicating possible horizontal gene transfer events.

The genus Rhizopogon shows high species diversity, which are widely distributed in Europe and North America [5]. Over 150 species have been described in the Rhizopogon genus. Because Rhizopogon species are easily cultured, they have been frequently used to study the evolution and genetics of ectomycorrhizal fungi [55]. Considering that macrofungi have limited identifiable morphological characteristics, it is difficult to classify and identify species by morphology alone accurately [56]. The introduction of molecular markers, such as rDNA ITS sequence, nuc-ssu, nuc-lsu, atp6, mt-lsu and so on $[2,3,9]$, has promoted the development of population genetics, taxonomy and biogeography of Rhizopogon species. However, as an important group of ectomycorrhizal fungi, no mitogenome has been reported in the Rhizopogon genus or even the Rhizopogonaceae family, which limits a comprehensive understanding of the genetics and phylogeny of this ectomycorrhizal fungal genus. In this study, we obtained an identical and well-supported tree topology based on the combined mitochondrial gene set, wherein the Rhizopogon genus was found having a close phylogenetic relationship with Agaricales species. The results showed that mitochondrial genes were reliable tools for studying phylogenetic relationships of Agaricomycotina. Fungi are widely distributed in the world and have complex taxonomic systems. More fungal mitogenomes are needed in further study to reveal the origin, evolution and genetic differentiation of fungi.

\section{Materials and Methods}

\subsection{De Novo Assembly and Annotation of Mitogenomes}

Raw data of the R. salebrosus and R. vinicolor genome sequencings were downloaded from the Joint Genome Institute (JGI) database. These sequence data were produced by the US Department of Energy Joint Genome Institute (https://www.jgi.doe.gov/) in collaboration with the user community [55]. Clean reads were obtained through a series of quality control steps from the raw data. De novo assembly of the two mitogenomes was performed as implemented by SPAdes 3.9 [57] using the obtained clean data. The software MITObim V1.9 [58] was used to fill gaps among contigs. The complete mitogenomes of $R$. salebrosus and R. vinicolor were obtained, and then annotated combining the results of the MFannot tool [59] and MITOS [60], both based on the genetic code 4. The PCGs, tRNA genes and rRNA genes were preliminarily annotated based on the two software. PCGs were then predicted or modified using the NCBI Open Reading Frame Finder [61] and annotated via BLASTP searches against the NCBI non-redundant protein sequence database [62]. PCGs with no significant similarity to previously characterized proteins were annotated as hypothetical proteins. tRNA genes were also predicted using the tRNAscan-SE 1.3.1 program [63]. Intron-exon borders of PCGs were verified using exonerate v2.2 [64].

\subsection{Sequence Analysis}

Base composition of the two mitogenomes was analyzed using the DNASTAR Lasergene v7.1 (http://www.dnastar.com/). Strand asymmetry of the two mitogenomes was assessed according to the following formulas: AT skew $=[\mathrm{A}-\mathrm{T}] /[\mathrm{A}+\mathrm{T}]$, and GC skew $=[\mathrm{G}-\mathrm{C}] /[\mathrm{G}+\mathrm{C}][65]$. Genetic distances between each pair of the 15 core PCGs (atp6, atp8, atp9, cob, cox1, cox2, cox3, nad1, nad2, nad3, nad4, nad4L, nad5, nad6, and rps3) were calculated with MEGA v6.06 [66], using the Kimura-2-parameter (K2P) model. We used the DnaSP v6 [67] to calculate the nonsynonymous substitution rate (Ka) and the synonymous substitution rate (Ks) for all the 15 core PCGs in the two Rhizopogon mitogenomes. Codon usage analysis was conducted using the Sequence Manipulation Suite [68], based on the genetic code 4. Genome synteny of the two Rhizopogon mitogenomes and representative species from other genera were analyzed using the Mauve v2.4.0 [69]. 


\subsection{Repetitive Elements Analysis}

To determine whether there is intra-genomic duplication of large fragments and interspersed repeats in the two Rhizopogon mitogenomes, BLASTn searches of the whole mitogenomes against themselves were performed at an $\mathrm{E}$ value of $<10^{-10}$. Tandem repeats ( $>10 \mathrm{bp}$ in length) in the two mitogenomes were detected using the Tandem Repeats Finder [70] with default parameters. In addition, repeated sequences were searched by REPuter [71] to identify forward (direct), reverse, complemented, and palindromic (reverse complemented) repeats in the two mitogenomes. To identify any gene segments that may have transferred between the mitochondrial and nuclear genomes of the two species, we performed BLASTn searches of the two mitogenomes against their previously published nuclear genomes (PVYR00000000.1 and LYZI00000000.1) [55].

\subsection{Intron Analysis}

Group I introns in the two Rhizopogon mitogenomes were classified into different position classes (Pcls) according to the method described by Férandon et al. [30]. Each Pcl was constituted by introns inserted at the same position in the coding region of the PCGs. Introns of the same Pcls and that contained high sequence similarities were considered to be homologous. Different Pcls showed low sequence similarities and contained non-homologous mobile genetic elements. The Pcls of cox 1 gene were named by letters according to the similarity with the described Pcls [30]. Pcls of $\operatorname{cox} 2, \operatorname{cox} 3, \operatorname{cob}$, nad1, nad5, $r n l$ genes were named by number according to the insert position in the coding region of host gene.

\subsection{Phylogenetic Analysis}

In order to investigate the phylogenetic status of the two Rhizopogon species among Agaricomycotina subphylum, we constructed a phylogenetic tree of 41 Agaricomycotina species based on the combined mitochondrial gene set (15 core PCGs + two rRNA genes). Single mitochondrial genes were first aligned using MAFFT v7.037 [72] and then these alignments were concatenated using SequenceMatrix v1.7.8 [73]. A preliminary partition homogeneity test was carried out to detect potential phylogenetic conflicts between different genes. Best-fit models of evolution and partitioning schemes for the gene set were determined according to PartitionFinder 2.1.1 [74]. MrBayes v3.2.6 [75] was used to construct the phylogenetic tree using Bayesian inference (BI) method based on the combined gene set. Two independent runs with four chains (three heated and one cold) each were conducted simultaneously for $2 \times 10^{6}$ generations. Each run was sampled every 100 generations. We assumed that stationarity had been reached when estimated sample size (ESS) was greater than 100, and the potential scale reduction factor (PSRF) approached 1.0. The first $25 \%$ samples were discarded as burn-in, and the remaining trees were used to calculate Bayesian posterior probabilities (BPP) in a $50 \%$ majority-rule consensus tree [47]. We also construct the phylogenetic tree using maximum likelihood (ML) method based on the combined gene set using RA $\times$ ML v8.0.0 [76].

\subsection{Availability of Data}

The R. salebrosus and R. vinicolor mitogenome sequences were submitted to GenBank under accession number MH794152 and MH794153, respectively.

Supplementary Materials: Supplementary materials can be found at http://www.mdpi.com/1422-0067/20/20/ 5167/s1.

Author Contributions: Formal analysis, Q.L., Y.R. and Y.S.; Funding acquisition, G.Z.; Investigation, Q.L. and Y.R.; Project administration, X.S.; Writing - original draft, Q.L.; Writing - review \& editing, Q.L., L.P. and J.Z.

Funding: This research was financially supported by the project of Ministry of Science and Technology of People's Republic of China (2018YFC1602101) and the project of Science \& Technology Department of Sichuan Province (19ZDYF2746) 
Acknowledgments: We thank Thomas D. Bruns for his suggestions on revision of the manuscript and for the raw data usage permission provided by Thomas D. Bruns.

Conflicts of Interest: The authors declare that they have no conflict of interest.

\section{References}

1. Franco, A.R.; Sousa, N.R.; Ramos, M.A.; Oliveira, R.S.; Castro, P.M. Diversity and persistence of ectomycorrhizal fungi and their effect on nursery-inoculated Pinus pinaster in a post-fire plantation in Northern Portugal. Microb. Ecol. 2014, 68, 761-772. [CrossRef] [PubMed]

2. Sulzbacher, M.A.; Grebenc, T.; Garcia, M.A.; Silva, B.D.; Silveira, A.; Antoniolli, Z.I.; Marinho, P.; Munzenberger, B.; Telleria, M.T.; Baseia, I.G.; et al. Molecular and morphological analyses confirm Rhizopogon verii as a widely distributed ectomycorrhizal false truffle in Europe, and its presence in South America. Mycorrhiza 2016, 26, 377-388. [CrossRef] [PubMed]

3. Dowie, N.J.; Grubisha, L.C.; Burton, B.A.; Klooster, M.R.; Miller, S.L. Increased phylogenetic resolution within the ecologically important Rhizopogon subgenus Amylopogon using 10 anonymous nuclear loci. Mycologia 2017, 109, 35-45. [CrossRef] [PubMed]

4. Grubisha, L.C.; Bergemann, S.E.; Bruns, T.D. Host islands within the California Northern Channel Islands create fine-scale genetic structure in two sympatric species of the symbiotic ectomycorrhizal fungus Rhizopogon. Mol. Ecol. 2007, 16, 1811-1822. [CrossRef]

5. Grubisha, L.C.; Trappe, J.M.; Molina, R.; Spatafora, J.W. Biology of the ectomycorrhizal genus Rhizopogon. VI. Re-examination of infrageneric relationships inferred from phylogenetic analyses of ITS sequences. Mycologia 2002, 94, 607-619. [CrossRef]

6. Ducic, T.; Parlade, J.; Polle, A. The influence of the ectomycorrhizal fungus Rhizopogon subareolatus on growth and nutrient element localisation in two varieties of Douglas fir (Pseudotsuga menziesii var. menziesii and var. glauca) in response to manganese stress. Mycorrhiza 2008, 18, 227-239. [CrossRef]

7. Rincon, A.; de Felipe, M.R.; Fernandez-Pascual, M. Inoculation of Pinus halepensis Mill. with selected ectomycorrhizal fungi improves seedling establishment 2 years after planting in a degraded gypsum soil. Mycorrhiza 2007, 18, 23-32. [CrossRef]

8. Sousa, N.R.; Ramos, M.A.; Marques, A.P.; Castro, P.M. The effect of ectomycorrhizal fungi forming symbiosis with Pinus pinaster seedlings exposed to cadmium. Sci. Total Environ. 2012, 414, 63-67. [CrossRef]

9. Bubriski, R.; Kennedy, P. A molecular and morphological analysis of the genus Rhizopogon subgenus Villosuli section Villosuli as a preface to ecological monitoring. Mycologia 2014, 106, 353-361. [CrossRef]

10. Mujic, A.B.; Hosaka, K.; Spatafora, J.W. Rhizopogon togasawariana sp. nov., the first report of Rhizopogon associated with an Asian species of Pseudotsuga. Mycologia 2014, 106, 105-112. [CrossRef]

11. Corradi, N.; Bonen, L. Mitochondrial genome invaders: An unselfish role as molecular markers. New Phytol. 2012, 196, 963-965. [CrossRef] [PubMed]

12. Lassiter, E.S.; Russ, C.; Nusbaum, C.; Zeng, Q.; Saville, A.C.; Olarte, R.A.; Carbone, I.; Hu, C.H.; Seguin-Orlando, A.; Samaniego, J.A.; et al. Mitochondrial genome sequences reveal evolutionary relationships of the Phytophthora 1c clade species. Curr. Genet. 2015, 61, 567-577. [CrossRef] [PubMed]

13. Delsuc, F.; Stanhope, M.J.; Douzery, E.J. Molecular systematics of armadillos (Xenarthra, Dasypodidae): Contribution of maximum likelihood and Bayesian analyses of mitochondrial and nuclear genes. Mol. Phylogenetics Evol. 2003, 28, 261-275. [CrossRef]

14. McBride, H.M.; Neuspiel, M.; Wasiak, S. Mitochondria: More than just a powerhouse. Curr. Biol. 2006, 16, R551-560. [CrossRef]

15. Ernster, L.; Schatz, G. Mitochondria: A historical review. J. Cell Biol. 1981, 91, 227s-255s. [CrossRef]

16. Basse, C.W. Mitochondrial inheritance in fungi. Curr. Opin. Microbiol. 2010, 13, 712-719. [CrossRef]

17. Anderson, S.; Bankier, A.T.; Barrell, B.G.; de Bruijn, M.H.; Coulson, A.R.; Drouin, J.; Eperon, I.C.; Nierlich, D.P.; Roe, B.A.; Sanger, F.; et al. Sequence and organization of the human mitochondrial genome. Nature 1981, 290, 457-465. [CrossRef]

18. Boore, J.L. Animal mitochondrial genomes. Nucleic Acids Res. 1999, 27, 1767-1780. [CrossRef]

19. Lang, B.F.; Gray, M.W.; Burger, G. Mitochondrial genome evolution and the origin of eukaryotes. Annu. Rev. Genet. 1999, 33, 351-397. [CrossRef] 
20. Barr, C.M.; Neiman, M.; Taylor, D.R. Inheritance and recombination of mitochondrial genomes in plants, fungi and animals. New Phytol. 2005, 168, 39-50. [CrossRef]

21. Li, H.; Shao, R.; Song, N.; Song, F.; Jiang, P.; Li, Z.; Cai, W. Higher-level phylogeny of paraneopteran insects inferred from mitochondrial genome sequences. Sci. Rep. 2015, 5, 8527. [CrossRef] [PubMed]

22. Satoh, T.P.; Miya, M.; Mabuchi, K.; Nishida, M. Structure and variation of the mitochondrial genome of fishes. BMC Genom. 2016, 17, 719. [CrossRef] [PubMed]

23. Paquin, B.; Laforest, M.J.; Forget, L.; Roewer, I.; Wang, Z.; Longcore, J.; Lang, B.F. The fungal mitochondrial genome project: Evolution of fungal mitochondrial genomes and their gene expression. Curr. Genet. 1997, 31, 380-395. [CrossRef] [PubMed]

24. Aguileta, G.; de Vienne, D.M.; Ross, O.N.; Hood, M.E.; Giraud, T.; Petit, E.; Gabaldon, T. High variability of mitochondrial gene order among fungi. Genome Biol. Evol. 2014, 6, 451-465. [CrossRef]

25. Li, Q.; Chen, C.; Xiong, C.; Jin, X.; Chen, Z.; Huang, W. Comparative mitogenomics reveals large-scale gene rearrangements in the mitochondrial genome of two Pleurotus species. Appl. Microbiol. Biotechnol. 2018, 102, 6143-6153. [CrossRef]

26. Li, Q.; Wang, Q.; Jin, X.; Chen, Z.; Xiong, C.; Li, P.; Liu, Q.; Huang, W. Characterization and comparative analysis of six complete mitochondrial genomes from ectomycorrhizal fungi of the Lactarius genus and phylogenetic analysis of the Agaricomycetes. Int. J. Biol. Macromol. 2019, 121, 249-260. [CrossRef] [PubMed]

27. Li, Q.; Wang, Q.; Chen, C.; Jin, X.; Chen, Z.; Xiong, C.; Li, P.; Zhao, J.; Huang, W. Characterization and comparative mitogenomic analysis of six newly sequenced mitochondrial genomes from ectomycorrhizal fungi (Russula) and phylogenetic analysis of the Agaricomycetes. Int. J. Biol. Macromol. 2018, 119, 792-802. [CrossRef]

28. Hamari, Z.; Juhasz, A.; Kevei, F. Role of mobile introns in mitochondrial genome diversity of fungi (a mini review). Acta Microbiol. Et Immunol. Hung. 2002, 49, 331-335. [CrossRef]

29. Mardanov, A.V.; Beletsky, A.V.; Kadnikov, V.V.; Ignatov, A.N.; Ravin, N.V. The 203 kbp mitochondrial genome of the phytopathogenic fungus Sclerotinia borealis reveals multiple invasions of introns and genomic duplications. PLOS ONE 2014, 9, e107536. [CrossRef]

30. Ferandon, C.; Xu, J.; Barroso, G. The $135 \mathrm{kbp}$ mitochondrial genome of Agaricus bisporus is the largest known eukaryotic reservoir of group I introns and plasmid-related sequences. Fungal Genet. Biol. 2013, 55, 85-91. [CrossRef]

31. Li, Q.; Wang, Q.; Jin, X.; Chen, Z.; Xiong, C.; Li, P.; Zhao, J.; Huang, W. Characterization and comparison of the mitochondrial genomes from two Lyophyllum fungal species and insights into phylogeny of Agaricomycetes. Int. J. Biol. Macromol. 2019, 121, 364-372. [CrossRef] [PubMed]

32. Burke, J.M. Molecular genetics of group I introns: RNA structures and protein factors required for splicing-a review. Gene 1988, 73, 273-294. [CrossRef]

33. Repar, J.; Warnecke, T. Mobile Introns Shape the Genetic Diversity of Their Host Genes. Genetics 2017, 205, 1641-1648. [CrossRef] [PubMed]

34. Formighieri, E.F.; Tiburcio, R.A.; Armas, E.D.; Medrano, F.J.; Shimo, H.; Carels, N.; Goes-Neto, A.; Cotomacci, C.; Carazzolle, M.F.; Sardinha-Pinto, N.; et al. The mitochondrial genome of the phytopathogenic basidiomycete Moniliophthora perniciosa is $109 \mathrm{~kb}$ in size and contains a stable integrated plasmid. Mycol. Res. 2008, 112, 1136-1152. [CrossRef] [PubMed]

35. Costa, G.G.; Cabrera, O.G.; Tiburcio, R.A.; Medrano, F.J.; Carazzolle, M.F.; Thomazella, D.P.; Schuster, S.C.; Carlson, J.E.; Guiltinan, M.J.; Bailey, B.A.; et al. The mitochondrial genome of Moniliophthora roreri, the frosty pod rot pathogen of cacao. Fungal Biol. 2012, 116, 551-562. [CrossRef]

36. James, T.Y.; Kauff, F.; Schoch, C.L.; Matheny, P.B.; Hofstetter, V.; Cox, C.J.; Celio, G.; Gueidan, C.; Fraker, E.; Miadlikowska, J.; et al. Reconstructing the early evolution of Fungi using a six-gene phylogeny. Nature 2006, 443, 818-822. [CrossRef]

37. Sandor, S.; Zhang, Y.; Xu, J. Fungal mitochondrial genomes and genetic polymorphisms. Appl. Microbiol. Biotechnol. 2018, 102, 9433-9448. [CrossRef]

38. Deng, Y.; Hsiang, T.; Li, S.; Lin, L.; Wang, Q.; Chen, Q.; Xie, B.; Ming, R. Comparison of the Mitochondrial Genome Sequences of Six Annulohypoxylon stygium Isolates Suggests Short Fragment Insertions as a Potential Factor Leading to Larger Genomic Size. Front. Microbiol. 2018, 9, 2079. [CrossRef] 
39. Salavirta, H.; Oksanen, I.; Kuuskeri, J.; Makela, M.; Laine, P.; Paulin, L.; Lundell, T. Mitochondrial genome of Phlebia radiata is the second largest (156 kbp) among fungi and features signs of genome flexibility and recent recombination events. PLoS ONE 2014, 9, e97141. [CrossRef]

40. Yang, R.; Li, Y.; Song, X.; Tang, L.; Li, C.; Tan, Q.; Bao, D. The complete mitochondrial genome of the widely cultivated edible fungus Lentinula edodes. Mitochondrial Dna Part B 2017, 2, 13-14. [CrossRef]

41. Stajich, J.E.; Wilke, S.K.; Ahren, D.; Au, C.H.; Birren, B.W.; Borodovsky, M.; Burns, C.; Canback, B.; Casselton, L.A.; Cheng, C.K.; et al. Insights into evolution of multicellular fungi from the assembled chromosomes of the mushroom Coprinopsis cinerea (Coprinus cinereus). Proc. Natl. Acad. Sci. USA 2010, 107, 11889-11894. [CrossRef] [PubMed]

42. Specht, C.A.; Novotny, C.P.; Ullrich, R.C. Mitochondrial DNA of Schizophyllum commune: Restriction map, genetic map, and mode of inheritance. Curr. Genet. 1992, 22, 129-134. [CrossRef] [PubMed]

43. Kanzi, A.M.; Wingfield, B.D.; Steenkamp, E.T.; Naidoo, S.; van der Merwe, N.A. Intron Derived Size Polymorphism in the Mitochondrial Genomes of Closely Related Chrysoporthe Species. PLoS ONE 2016, 11, e0156104. [CrossRef] [PubMed]

44. Munoz-Gomez, S.A.; Wideman, J.G.; Roger, A.J.; Slamovits, C.H. The Origin of Mitochondrial Cristae from Alphaproteobacteria. Mol. Biol. Evol. 2017, 34, 943-956. [CrossRef]

45. Adams, K.L.; Palmer, J.D. Evolution of mitochondrial gene content: Gene loss and transfer to the nucleus. Mol. Phylogenetics Evol. 2003, 29, 380-395. [CrossRef]

46. Li, Q.; Wang, Q.; Jin, X.; Chen, Z.; Xiong, C.; Li, P.; Zhao, J.; Huang, W. The first complete mitochondrial genome from the family Hygrophoraceae (Hygrophorus russula) by next-generation sequencing and phylogenetic implications. Int. J. Biol. Macromol. 2019, 122, 1313-1320. [CrossRef]

47. Li, Q.; Yang, M.; Chen, C.; Xiong, C.; Jin, X.; Pu, Z.; Huang, W. Characterization and phylogenetic analysis of the complete mitochondrial genome of the medicinal fungus Laetiporus sulphureus. Sci. Rep. 2018, 8, 9104. [CrossRef]

48. Lin, L.; Cui, P.; Qiu, Z.; Wang, M.; Yu, Y.; Wang, J.; Sun, Q.; Zhao, H. The mitochondrial tRNA(Ala) 5587T > $\mathrm{C}$ and $\mathrm{tRNA}(\mathrm{Leu}(\mathrm{CUN}))$ 12280A $>\mathrm{G}$ mutations may be associated with hypertension in a Chinese family. Exp. Ther. Med. 2019, 17, 1855-1862.

49. Ding, Y.; Teng, Y.S.; Zhuo, G.C.; Xia, B.H.; Leng, J.H. The Mitochondrial tRNAHis G12192A Mutation May Modulate the Clinical Expression of Deafness-Associated tRNAThr G15927A Mutation in a Chinese Pedigree. Curr. Mol. Med. 2019, 19, 136-146. [CrossRef]

50. Sankoff, D.; Leduc, G.; Antoine, N.; Paquin, B.; Lang, B.F.; Cedergren, R. Gene order comparisons for phylogenetic inference: Evolution of the mitochondrial genome. Proc. Natl. Acad. Sci. USA 1992, 89, 6575-6579. [CrossRef]

51. Tang, B.P.; Xin, Z.Z.; Liu, Y.; Zhang, D.Z.; Wang, Z.F.; Zhang, H.B.; Chai, X.Y.; Zhou, C.L.; Liu, Q.N. The complete mitochondrial genome of Sesarmops sinensis reveals gene rearrangements and phylogenetic relationships in Brachyura. PLoS ONE 2017, 12, e0179800. [CrossRef] [PubMed]

52. Xia, Y.; Zheng, Y.; Murphy, R.W.; Zeng, X. Intraspecific rearrangement of mitochondrial genome suggests the prevalence of the tandem duplication-random loss (TDLR) mechanism in Quasipaa boulengeri. BMC Genom. 2016, 17, 965. [CrossRef] [PubMed]

53. Lavrov, D.V.; Boore, J.L.; Brown, W.M. Complete mtDNA sequences of two millipedes suggest a new model for mitochondrial gene rearrangements: Duplication and nonrandom loss. Mol. Biol. Evol. 2002, 19, 163-169. [CrossRef] [PubMed]

54. Li, Q.; Liao, M.; Yang, M.; Xiong, C.; Jin, X.; Chen, Z.; Huang, W. Characterization of the mitochondrial genomes of three species in the ectomycorrhizal genus Cantharellus and phylogeny of Agaricomycetes. Int. J. Biol. Macromol. 2018, 118, 756-769. [CrossRef] [PubMed]

55. Mujic, A.B.; Kuo, A.; Tritt, A.; Lipzen, A.; Chen, C.; Johnson, J.; Sharma, A.; Barry, K.; Grigoriev, I.V.; Spatafora, J.W. Comparative Genomics of the Ectomycorrhizal Sister Species Rhizopogon vinicolor and Rhizopogon vesiculosus (Basidiomycota: Boletales) Reveals a Divergence of the Mating Type B Locus. G3 2017, 7, 1775-1789. [CrossRef]

56. Cho, H.J.; Park, M.S.; Lee, H.; Oh, S.Y.; Wilson, A.W.; Mueller, G.M.; Lim, Y.W. A systematic revision of the ectomycorrhizal genus Laccaria from Korea. Mycologia 2018, 110, 948-961. [CrossRef] 
57. Bankevich, A.; Nurk, S.; Antipov, D.; Gurevich, A.A.; Dvorkin, M.; Kulikov, A.S.; Lesin, V.M.; Nikolenko, S.I.; Pham, S.; Prjibelski, A.D.; et al. SPAdes: A new genome assembly algorithm and its applications to single-cell sequencing. J. Comput. Biol. : A J. Comput. Mol. Cell Biol. 2012, 19, 455-477. [CrossRef]

58. Hahn, C.; Bachmann, L.; Chevreux, B. Reconstructing mitochondrial genomes directly from genomic next-generation sequencing reads-a baiting and iterative mapping approach. Nucleic Acids Res. 2013, 41, e129. [CrossRef]

59. Valach, M.; Burger, G.; Gray, M.W.; Lang, B.F. Widespread occurrence of organelle genome-encoded 5S rRNAs including permuted molecules. Nucleic Acids Res. 2014, 42, 13764-13777. [CrossRef]

60. Bernt, M.; Donath, A.; Juhling, F.; Externbrink, F.; Florentz, C.; Fritzsch, G.; Putz, J.; Middendorf, M.; Stadler, P.F. MITOS: Improved de novo metazoan mitochondrial genome annotation. Mol. Phylogenetics Evol. 2013, 69, 313-319. [CrossRef]

61. Coordinators, N.R. Database resources of the National Center for Biotechnology Information. Nucleic Acids Res. 2017, 45, D12-D17.

62. Bleasby, A.J.; Wootton, J.C. Construction of validated, non-redundant composite protein sequence databases. Protein Eng. 1990, 3, 153-159. [CrossRef] [PubMed]

63. Lowe, T.M.; Chan, P.P. tRNAscan-SE On-line: Integrating search and context for analysis of transfer RNA genes. Nucleic Acids Res. 2016, 44, W54-57. [CrossRef] [PubMed]

64. Slater, G.S.; Birney, E. Automated generation of heuristics for biological sequence comparison. BMC Bioinform. 2005, 6, 31. [CrossRef] [PubMed]

65. Wang, J.; Zhang, L.; Zhang, Q.L.; Zhou, M.Q.; Wang, X.T.; Yang, X.Z.; Yuan, M.L. Comparative mitogenomic analysis of mirid bugs (Hemiptera: Miridae) and evaluation of potential DNA barcoding markers. PeerJ 2017, 5, e3661. [CrossRef] [PubMed]

66. Caspermeyer, J. MEGA Evolutionary Software Re-Engineered to Handle Today's Big Data Demands. Mol. Biol. Evol. 2016, 33, 1887. [CrossRef] [PubMed]

67. Rozas, J.; Ferrer-Mata, A.; Sanchez-DelBarrio, J.C.; Guirao-Rico, S.; Librado, P.; Ramos-Onsins, S.E.; Sanchez-Gracia, A. DnaSP 6: DNA Sequence Polymorphism Analysis of Large Data Sets. Mol. Biol. Evol. 2017, 34, 3299-3302. [CrossRef]

68. Stothard, P. The sequence manipulation suite: JavaScript programs for analyzing and formatting protein and DNA sequences. Bio. Techniques. 2000, 28, 1102-1104. [CrossRef]

69. Darling, A.C.; Mau, B.; Blattner, F.R.; Perna, N.T. Mauve: Multiple alignment of conserved genomic sequence with rearrangements. Genome Res. 2004, 14, 1394-1403. [CrossRef]

70. Benson, G. Tandem repeats finder: A program to analyze DNA sequences. Nucleic Acids Res. 1999, 27, 573-580. [CrossRef]

71. Kurtz, S.; Choudhuri, J.V.; Ohlebusch, E.; Schleiermacher, C.; Stoye, J.; Giegerich, R. REPuter: The manifold applications of repeat analysis on a genomic scale. Nucleic Acids Res 2001, 29, 4633-4642. [CrossRef] [PubMed]

72. Katoh, K.; Rozewicki, J.; Yamada, K.D. MAFFT online service: Multiple sequence alignment, interactive sequence choice and visualization. Brief. Bioinform. 2017. [CrossRef] [PubMed]

73. Vaidya, G.; Lohman, D.L.; Meier, R. SequenceMatrix: Concatenation software for the fast assembly of multi-gene datasets with character set and codon information. Cladistics 2011, 27, 171-180. [CrossRef]

74. Lanfear, R.; Frandsen, P.B.; Wright, A.M.; Senfeld, T.; Calcott, B. PartitionFinder 2: New Methods for Selecting Partitioned Models of Evolution for Molecular and Morphological Phylogenetic Analyses. Mol. Biol. Evol. 2017, 34, 772-773. [CrossRef]

75. Ronquist, F.; Teslenko, M.; van der Mark, P.; Ayres, D.L.; Darling, A.; Hohna, S.; Larget, B.; Liu, L.; Suchard, M.A.; Huelsenbeck, J.P. MrBayes 3.2: Efficient Bayesian phylogenetic inference and model choice across a large model space. Syst. Biol. 2012, 61, 539-542. [CrossRef]

76. Stamatakis, A. RAxML version 8: A tool for phylogenetic analysis and post-analysis of large phylogenies. Bioinformatics 2014, 30, 1312-1313. [CrossRef]

(C) 2019 by the authors. Licensee MDPI, Basel, Switzerland. This article is an open access article distributed under the terms and conditions of the Creative Commons Attribution (CC BY) license (http://creativecommons.org/licenses/by/4.0/). 